\title{
First experience of laparoscopic adjustable banded sleeve gastrectomy for an extremely obese patient
}

\author{
Khatkov IE, ${ }^{1,2}$ Askerkhanov RG, ${ }^{1,2}$ Feidorov IJ, ${ }^{1,2}$ Bodunova NA ${ }^{1}$ \\ 'Moscow Clinical and Scientific Centre, Moscow, Russia \\ ${ }^{2}$ Moscow State University of Medicine and Dentistry, Moscow, Russia
}

\begin{abstract}
Patients with body mass index (BMI) over $60 \mathrm{~kg} / \mathrm{m}^{2}$ are considered super-super obese. This patient group, as well as patients with extreme co-morbidities, creates challenging conditions for bariatric surgery. Each step of laparoscopy, including insufflation, trocar placement, dissection, and performing complex procedures like bypass becomes technically more difficult. Furthermore, there is increased risk of postoperative complications, morbidity, and mortality in these groups. Presently described is adjustable gastric banded sleeve gastrectomy (LabSG) performed in 38-year-old female with BMI of $84.3 \mathrm{~kg} / \mathrm{m}^{2}$. Following an uneventful postoperative course, she lost $100 \mathrm{~kg}$ in 12 -month period and BMI was reduced to $52.7 \mathrm{~kg} / \mathrm{m}^{2}$. LabSG seems to be a safe and effective alternative for super-super obese patients at experienced centers.
\end{abstract}

Keywords: Adjustable gastric banded sleeve gastrectomy; adjustable gastric banding; morbid obesity; sleeve gastrectomy; super-super obesity.

\section{Introduction}

Surgical approach is the most effective treatment for patients with morbid obesity ${ }^{[1]}$ It's generally known that surgical treatment of super-super obesity (BMI $>60 \mathrm{~kg} /$ $\mathrm{m}^{2}$ ) and high-risk patients with comorbidities is related with an increased risk of postoperative morbidity and mortality after bariatric surgery. ${ }^{[2]}$ Moreover, there are some specific difficulties in laparoscopic surgery for extremely obese patients such as an increased resistance of abdominal wall, necessity for an increased pressure of $\mathrm{CO}_{2}$ in abdomen, longer instruments, and sometimes necessity for placing additional ports or modificating port sites.
The selection of bariatric procedure in case of extremely obese patients should be done in favor of the least traumatic procedure, given the minimal risks of complications. Sleeve gastrectomy is a recently used surgical technique with an acceptable rate of postoperative complications. ${ }^{[3]}$ It was described as the first step before a biliopancreatic diversion with duodenal switch, but it is also used as an independent procedure. The advantages of this procedure include lack of an intestinal bypass, thus avoiding gastrointestinal anastomoses, metabolic disorders, and internal hernias, shorter operating times, and 
no implantation of a foreign body. ${ }^{[4]}$ It is reported that with LSG about forty-eight percent of excess weight is lost after 6 to 8 years follow-up. ${ }^{[5]}$

Laparoscopic sleeve gastrectomy was described as a revision bariatric procedure for failed gastric banding. ${ }^{[6-8]}$ There are some articles about banded sleeve gastrectomy in case of extremely obese patients for the prevention of gastric dilatation. ${ }^{[9-11]}$

This case report presents our first experience of laparoscopic adjustable banded sleeve gastrectomy with oneyear follow-up in the case of a super-super obese patient.

\section{Case Report}

A 38-year-old female patient weighing $267 \mathrm{~kg}$ and having a BMI of $84.3 \mathrm{~kg} / \mathrm{m}^{2}$ was admitted to our clinic so as to assess her present status for bariatric procedure. Her medical history suggested that in her twenties she weighed 70-74 kg with $178 \mathrm{~cm}$ height and worked as a confectioner. Later, she began to notice an increase in weight systematically about one or two kg per month. At the age of thirty, she weighed $120 \mathrm{~kg}$ (BMI $37.87 \mathrm{~kg} / \mathrm{m}^{2}$ ), then at the age of 34, her body weight further increased following pregnancy. Although she temporarily lost weight with diet and exercise, eventually she gained further weight and was $267 \mathrm{~kg}$ at the time of hospitalization for the bariatric procedure.

Her medical history revealed that she had contracted purulent meningitis, two cranial traumas and also she attempted to suicide twice with medicines and by stabbing. Furthermore, she suffered from rheumatism with heart disease, high grade myopia, varicose veins without any trophic changes, anxiety, and depression. Preoperative instrumental examination showed: upper endoscopy -duodenal reflux, ultrasound (thyroid, abdominal cavity and gynecology) -no significant changes, echocardiography -middle pulmonary hypertension; Doppler ultrasound of feet vessels was not informative, 24 hour electrocardiography with middle rate of ventricular ectopic beats (186) and low rate of supraventricular ectopic beats (16), and 24 hour monitoring of blood pressure with no pathological changes. In her laboratory tests, there was iron deficiency (without clinical signs). Her laboratory evaluation is summarized in Table 1.

During the preparation phase for bariatric surgery, a course of antidepressants (Zoloft $100 \mathrm{mg} /$ once per day) was initiated together with a light diet.

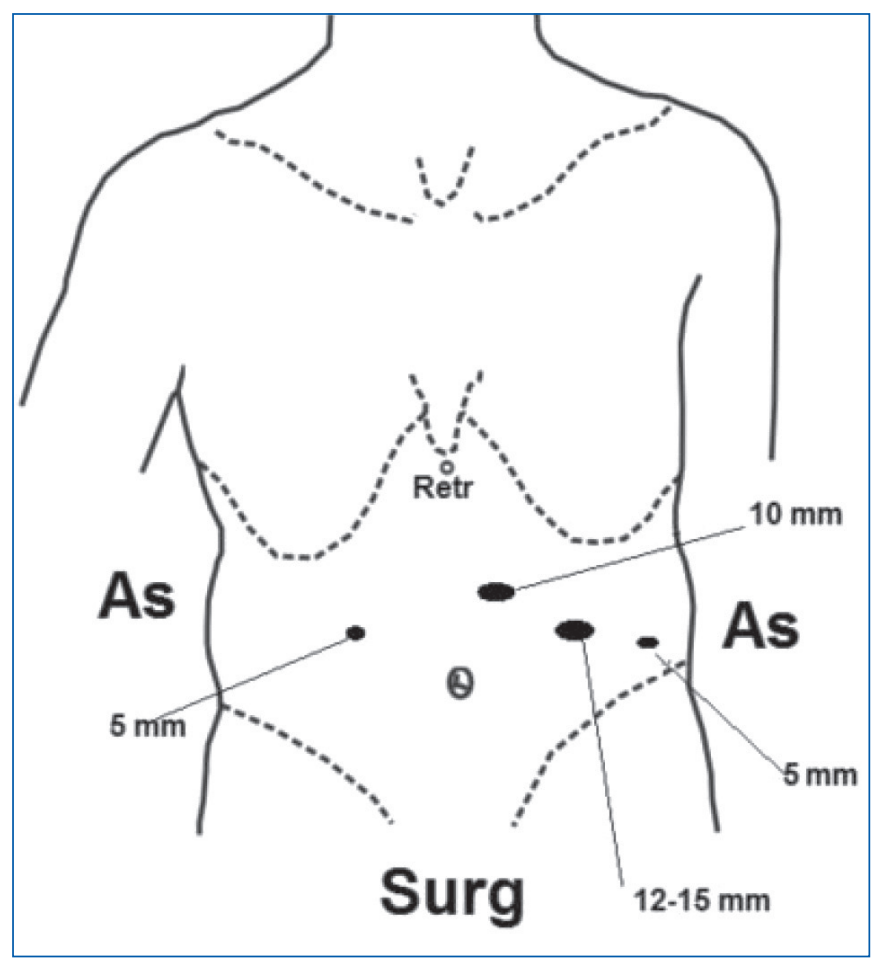

Figure 1. Surgical team and ports placement.

In April 2013, the patient underwent laparoscopic adjustable banded sleeve gastrectomy. Briefly, the patient was placed in the supine position with both legs abducted, and then Trendelenburg after first port placed. Four ports technique was used (Figure 1): $10 \mathrm{~mm}$-camera port, $12 \mathrm{~mm}$ -main surgeon port, $5 \mathrm{~mm}$-surgeon assistant port, $5 \mathrm{~mm}$ assistant port, and epigastric $5 \mathrm{~mm}$ port for Nathanson liver retractor to retract the left lateral liver segment. Gastric mobilization was performed by the Harmonic scalpel (Johnson\&Johnson, USA). The window into omental bursa was made about $5 \mathrm{~cm}$ proximal to the pylorus. Graeter gastric curvature was mobilized till the left diaphragmatic crus and after esophagus visualization, short gastric vessels were carefully sealed and divided. Sleeve was created on the $33 \mathrm{Fr}$ bougie by the Endo GIA stapler (Covidien, Ireland) using $45 \mathrm{~mm}$ green cartridge (2 pieces) and 60 $\mathrm{mm}$ blue cartridge (4 pieces). Different types of cartridges were used depending on the thickness of the gastric wall. Staple line was oversewn by the vicryl 3-0 run suture in order to prevent staple line leaks. Thereafter, the adjustable gastric banding system (Medsil, Russia) was placed on the gastric sleeve right below the esophago-gastric junction without gastro-gastric sutures, and thereby, the gastric band ring was fixed only in the lesser omentum. At the end of the surgery, abdominal cavity was drained in splenic sinus area and banding system port was placed on the aponeurosis of the external oblique abdominal 
Table 1. Laboratory examination before and 6 months after LabSG

\section{Object}

Before bariatric procedure

6 months after LabSG

Hemoglobin $(\mathrm{g} / \mathrm{dL})$

Protein total $(\mathrm{g} / \mathrm{L})$

Glucose (mmol/L)

Cholesterol (mmol/L)

HDL (High-density lipoproteins) ( $\mathrm{mmol} / \mathrm{L})$

LDL (Low-density lipoproteins) ( $\mathrm{mmol} / \mathrm{L})$

Potassium (mmol/L)

Sodium (mmol/L)

Calcium (mmol/L)

Iron (mkmol/L)

\section{5 \\ 66.9}

$5.4-5.9$

3.88

0.93

2.28

4.03

139.6

2.27

7.7
14.5

71.9

$5.37-7.09$

4.28

1.34

2.35

3.75

139.2

2.45

8.2

\section{Table 2. Vitamin levels at 6 and 9 months after surgery}

\section{Object}

Nicotinic acid $(17-85 \mathrm{mg} / \mathrm{mL})$

Vitamin C $(4-15 \mu \mathrm{g} / \mathrm{mL})$

Biotine $(>1250 \mu \mathrm{g} / \mathrm{L})$

Vitamin D (47.7-144 $\mu \mathrm{g} / \mathrm{L})$

Vitamin B1 $(30-66 \mu \mathrm{g} / \mathrm{L})$

Vitamin B2 (50-206)

Vitamin B5 (36-147 pg/mL)

Vitamin B6 $(4.8-17.7 \mu \mathrm{g} / \mathrm{L})$

Vitamin B9 $(3.8-23.2 \mathrm{ng} / \mathrm{mL})$

Vitamin B12 (25-500 pg/mL)

Retinol binding protein $(20-75 \mu \mathrm{mol} / \mathrm{L})$
6 months after LabSG

$\begin{array}{cc}15.92 & 46.72 \\ 7.3 & 8.7 \\ 1520 & 1740 \\ 16.7 & 40.22 \\ 10 & 15 \\ 58.8 & 98.0 \\ 23.92 & 52.3 \\ 2.4 & 3.5 \\ 0.7 & 5.0 \\ 588.9 & 415.7 \\ 36.1 & 25.4\end{array}$

muscles by the anterior axillary line. The patient had an uneventful postoperative period. She started drinking on the second day after surgery and had been on a soft diet for 3 weeks. On the third day after surgery, the patient was transferred to general therapy unit and then discharged at the $6^{\text {th }}$ postoperative day.

On the third and 6th month after surgery, a general checkup was performed for alimentary, laboratory and psychological status assessment and instrumental examination. There were no pathological changes in instrumental (X-ray barium scan, upper endoscopy and abdomen ultrasound scan) tests and the postoperative laboratory results are summarized in Table 1. Her psychiatric evaluation revealed signs of anxiety and depression six months after surgery, which were overcome with psychological support and a course of antidepressants. On the sixth and $9^{\text {th }}$ month after surgery, advanced laboratory tests were car- ried out and vitamins insufficiency was diagnosed (Table 2). In order to remedy vitamins malabsorption, vitamins (A, B1, B12, B9, and D) were prescribed. Weight loss one year after bariatric procedure was about $100 \mathrm{~kg}$ (BMI-52.7 $\mathrm{kg} / \mathrm{m}^{2}$ ). She presented a stable weight loss the whole year without band adjustments and a favorable psychological status with no condition of depression after psychotherapy sessions.

\section{Conclusion and Discussion}

This case presented laparoscopic adjustable banded sleeve gastrectomy as a safe and effective bariatric procedure for patients with high risks for surgery. Systematically carried out advanced laboratory tests, together with dietary corrections and psychological support (multidisciplinary approach) are required for better results in cases of extremely obese patients. 


\section{References}

1. Catheline JM, Fysekidis M, Dbouk R, Boschetto A, Bihan H, Reach $\mathrm{G}$, et al. Weight loss after sleeve gastrectomy in super superobesity. J Obes 2012;2012:959260.

2. Gagner M, Gumbs AA, Milone L, Yung E, Goldenberg L, Pomp A. Laparoscopic sleeve gastrectomy for the super-super-obese (body mass index $>60 \mathrm{~kg} / \mathrm{m}(2)$ ). Surg Today 2008;38:399-403.

3. Dillemans B, Van Cauwenberge S, Agrawal S, Van Dessel E, Mulier JP. Laparoscopic adjustable banded roux-en-y gastric bypass as a primary procedure for the super-super-obese (body mass index $>60 \mathrm{~kg} / \mathrm{m}^{2}$ ). BMC Surg 2010;10:33.

4. Eisenberg D, Bellatorre A, Bellatorre N. Sleeve gastrectomy as a stand-alone bariatric operation for severe, morbid, and super obesity. JSLS 2013;17:63-7.

5. Eid GM, Brethauer S, Mattar SG, Titchner RL, Gourash W, Schauer PR. Laparoscopic sleeve gastrectomy for super obese patients: forty-eight percent excess weight loss after 6 to 8 years with 93\% follow-up. Ann Surg 2012;256:262-5.

6. Marin-Perez P, Betancourt A, Lamota M, Lo Menzo E, Szom- stein S, Rosenthal R. Outcomes after laparoscopic conversion of failed adjustable gastric banding to sleeve gastrectomy or Roux-en-Y gastric bypass. Br J Surg 2014;101:254-60.

7. Silecchia G, Rizzello M, De Angelis F, Raparelli L, Greco F, Perrotta $\mathrm{N}$, et al. Laparoscopic sleeve gastrectomy as a revisional procedure for failed laparoscopic gastric banding with a "2-step approach": a multicenter study. Surg Obes Relat Dis 2014;10:626-31.

8. Liu KH, Diana M, Vix M, Mutter D, Wu HS, Marescaux J. Revisional surgery after failed adjustable gastric banding: institutional experience with 90 consecutive cases. Surg Endosc 2013;27:4044-8.

9. Alexander JW, Martin Hawver LR, Goodman HR. Banded sleeve gastrectomy-initial experience. Obes Surg 2009;19:1591-6.

10. Agrawal S, Van Dessel E, Akin F, Van Cauwenberge S, Dillemans B. Laparoscopic adjustable banded sleeve gastrectomy as a primary procedure for the super-super obese (body mass index $>60 \mathrm{~kg} / \mathrm{m} 2$ ). Obes Surg 2010;20:1161-3.

11. Karcz WK, Marjanovic G, Grueneberger J, Baumann T, Bukhari W, Krawczykowski D, et al. Banded sleeve gastrectomy using the GaBP ring-surgical technique. Obes Facts 2011;4:77-80. 